\title{
Edge Dominating Functions of Quadratic Residue Cayley Graphs
}

\author{
S. Jeelani Begum \\ Associate Professor \\ Department of Mathematics, MITS, Madanapalle, \\ $A P$, INDIA.
}

\author{
B. Maheswari \\ Professor, \\ Department of Mathematics, Sri Padmavati \\ Women's University, Tirupati, AP, INDIA.
}

\begin{abstract}
The concept of edge domination is introduced by Mitchell and Hedetniemi [6]. Further results on edge domination are given in Arumugam and Velammal [2]. Functional generalization for vertex subsets has been studied extensively in literature $[4,5]$. Cockayne and Mynhardt [3] have introduced that edge subsets may also be embedded into sets of functions and an analogous concept of convexity could also be developed. In this paper we obtain results on minimal edge dominating functions of $G\left(Z_{p}, Q\right)$ and the convexity of these functions are discussed. The theory of Edge Dominating Functions in quadratic residue Cayley graphs helps in finding optimal global and local alignments for the smooth conduction of a work and improves the ability of a task or a job in connected systems such as transportation process, communication tools, networks etc.
\end{abstract}

\section{Keywords}

Edge Dominating Functions - Minimal Edge Dominating Functions - Convexity.

\section{INTRODUCTION}

The quadratic residue Cayley graph $G\left(Z_{p}, Q\right)$, that is, the Cayley graph associated with the set of quadratic residues modulo an odd prime $\mathrm{p}$, is defined as follows.

Let $\mathrm{p}$ be an odd prime, $\mathrm{S}$, the set of quadratic residues modulo $\mathrm{p}$ and let $\mathrm{S}^{*}=\{\mathrm{s}, \mathrm{p}-\mathrm{s} / \mathrm{s}$ \& $\mathrm{S}, \mathrm{s}$ (1) $\mathrm{p}\}$. The quadratic residue Cayley graph $G\left(Z_{p}, Q\right)$ is defined as the graph whose vertex set is $Z_{p}=\{0,1,2,3, \ldots \ldots,(p-1)\}$ and the edge set $\quad E=\left\{(x, y) / x-y\right.$ or $y-x$ is in $\left.S^{*}\right\}$. Example: The Graph $\mathrm{G}\left(\mathrm{Z}_{\mathrm{p}}, \mathrm{Q}\right)$ for $\mathrm{p}=13$ is given below.

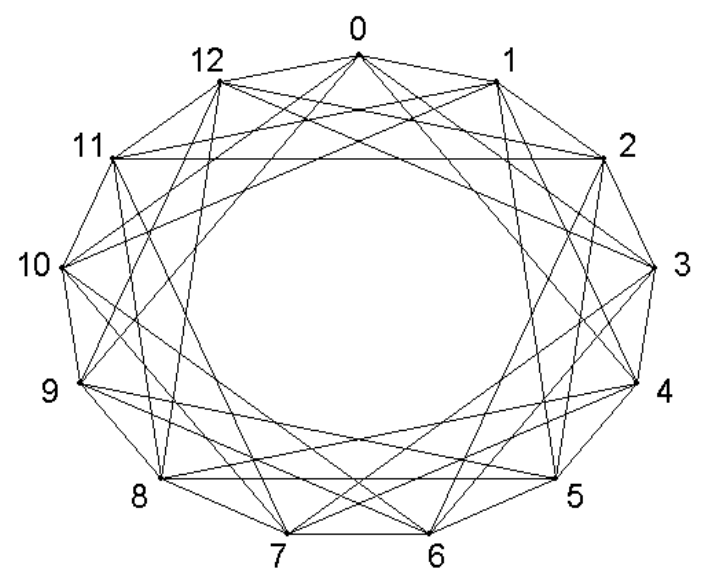

We now consider the definitions of edge dominating function, minimal edge dominating function.

Edge Dominating Set: Let $G(V, E)$ be a graph. A subset $F$ of $E$ is called an edge dominating set (EDS) if each edge in $E-F$ is adjacent to atleast one edge in F.

Minimal Edge Dominating Set: Let $\mathrm{G}(\mathrm{V}, \mathrm{E})$ be a graph. An EDS, $F$ is called a minimal edge dominating set (MEDS) if no proper subset of $\mathrm{F}$ is an EDS of G.

Edge Dominating Function: Let $\mathrm{G}(\mathrm{V}, \mathrm{E})$ be a graph. A function $f: E \rightarrow[0,1]$ is called an edge dominating function (EDF) if $\sum_{e^{\prime} \in N[e]} f\left(e^{\prime}\right) \geq 1$ for all $e \in E(G)$, where $\mathrm{N}[\mathrm{e}]$ is the closed neighbourhood of the edge e.

Minimal Edge Dominating Function: An EDF $f$ is called a minimal edge dominating function (MEDF), if for all functions $g: E \rightarrow[0,1]$ with $g<f$, g is not an edge dominating function.

Let $\mathrm{G}(\mathrm{V}, \mathrm{E})$ be a graph and $\mathrm{A}, \mathrm{B} \subseteq \mathrm{E}$. We say that A dominates $B$ if every edge in $\mathrm{B}-\mathrm{A}$ is adjacent to an edge in A and we write $A \rightarrow B$.

Let $f$ be any EDF of G. The boundary set $B_{f}^{\prime}$ and the positive set $P_{f}^{\prime}$ of $f$ are defined by

and

$$
B_{f}^{\prime}=\left\{e \in E: \sum_{e^{\prime} \in N[e]} f\left(e^{\prime}\right)=1\right\}
$$$$
P_{f}^{\prime}=\{e \in E: f(e)>0\} \text {. }
$$

We need the following result referred from Arumugam and Sitara Jerry [1].

Theorem 1.1: An EDF $f$ is a MEDF of $\mathrm{G}$ if and only if $B_{f}^{\prime} \rightarrow P_{f}^{\prime}$.

\section{MAIN RESULTS}

Theorem 2.1: Let $\mathrm{F}$ be a MEDS of $\mathrm{G}\left(\mathrm{Z}_{\mathrm{p}}, \mathrm{Q}\right)$. Then a function $f: E \rightarrow[0,1]$ defined by

$$
f(e)= \begin{cases}1, & \text { if } e \in F, \\ 0, & \text { otherwise. }\end{cases}
$$

becomes a MEDF of $\mathrm{G}\left(\mathrm{Z}_{\mathrm{p}}, \mathrm{Q}\right)$.

Proof: Consider $G\left(Z_{p}, Q\right)$. Let $F$ be a MEDS of $G\left(Z_{p}, Q\right)$. 
Let $|F|=\mathrm{n}>1$. Let $\mathrm{f}$ be the function defined as in the hypothesis. The summation value taken over the neighbourhood $\mathrm{N}[\mathrm{e}]$ of $\mathrm{e}$ Q $\mathrm{E}$ is

$$
\sum_{e^{\prime} \in N[e]} f\left(e^{\prime}\right)=\left\{\begin{array}{l}
1, \text { if anyone edge of } F \text { is in } N[e] \\
s \times 1, \text { if } s \text { edges of } F \text { are in } N[e]
\end{array}\right.
$$

where $\mathrm{s}<\mathrm{n}$ and $\mathrm{s}>1$.

Thus $\sum_{e^{\prime} \in N[e]} f\left(e^{\prime}\right) \geq 1, \quad \&$ e Q $\mathrm{E}$

Therefore $\mathrm{f}$ is an EDF.

We now check for the minimality of $\mathrm{f}$.

Define $g: E \rightarrow[0,1]$ by

$$
g(e)= \begin{cases}r, & \text { if } e=e_{i} \in F \\ 1, & \text { if } e \in F-\left\{e_{i}\right\} \\ 0, & \text { otherwise }\end{cases}
$$

where $0<\mathrm{r}<1$.

Since strict inequality holds at the edge e Q $\mathrm{F}$ of $\mathrm{E}$, it follows that $\mathrm{g}<\mathrm{f}$.

Now

$$
\sum_{e^{\prime} \in N[e]} g\left(e^{\prime}\right)=\left\{\begin{array}{l}
r, \text { if } e_{i} \in F \text { is in } N[e], \\
1, \text { if any one edge e of } F-\left\{e_{i}\right\} \text { is in } N[e], \\
s \times 1, \text { if } s \text { edges of } F-\left\{e_{i}\right\} \text { are in } N[e] .
\end{array}\right.
$$

So $\sum_{e^{\prime} \in N[e]} g\left(e^{\prime}\right) \geq 1, \&$ e ฉ $\mathrm{E}$.

This implies that $g$ is not an EDF. Since $r<1$ is arbitrary it follows that there exists no $\mathrm{g}<\mathrm{f}$ such that $\mathrm{g}$ is an EDF.

Thus $f$ is a MEDF of $G\left(Z_{p}, Q\right)$.

Theorem 2.2: Let $f_{1}$ and $f_{2}$ be two distinct MEDFs of $\mathrm{G}\left(\mathrm{Z}_{\mathrm{p}}, \mathrm{Q}\right)$ defined from $\mathrm{E}$ to $[0,1]$. Let $\mathrm{h}$ be the convex combination of $f_{1}$ and $f_{2}$. Then $B_{h}^{\prime}=B_{f_{1}}^{\prime} \cap B_{f_{2}}^{\prime}$ and $P_{h}^{\prime}=P_{f_{1}}^{\prime} \cup P_{f_{2}}^{\prime}$.

Proof: Consider $\mathrm{G}\left(\mathrm{Z}_{\mathrm{p}}, \mathrm{Q}\right)$. Let $f_{1}$ and $f_{2}$ be two distinct MEDFs. Let $h=\lambda_{1} f_{1}+\lambda_{2} f_{2}$, where $0<\lambda_{1}<1$,

$0<\lambda_{2}<1$, and $\lambda_{1}+\lambda_{2}=1$.

We now claim that $B_{h}^{\prime}=B_{f_{1}}^{\prime} \cap B_{f_{2}}^{\prime}$ and $P_{h}^{\prime}=P_{f_{1}}^{\prime} \cup P_{f_{2}}^{\prime}$. Let $e \in B_{f_{1}}^{\prime} \cap B_{f_{2}}^{\prime}$.

Then $\sum_{e^{\prime} \in N[e]} f_{i}\left(e^{\prime}\right)=1$, for $i=1,2$.

Now

$$
\begin{aligned}
\sum_{e^{\prime} \in N[e]} h\left(e^{\prime}\right) & =\sum_{e^{\prime} \in N[e]}\left[\sum_{i=1}^{2} \lambda_{i} f_{i}\right]\left(e^{\prime}\right) \\
& =\sum_{e^{\prime} \in N[e]}\left[\lambda_{1} f_{1}\left(e^{\prime}\right)+\lambda_{2} f_{2}\left(e^{\prime}\right)\right] \\
& =\lambda_{1} \sum_{e^{\prime} \in N[e]} f_{1}\left(e^{\prime}\right)+\lambda_{2} \sum_{e^{\prime} \in N[e]} f_{2}\left(e^{\prime}\right) \\
& =\lambda_{1} .1+\lambda_{2} .1=\lambda_{1}+\lambda_{2}=1 .
\end{aligned}
$$

Therefore $\sum_{e^{\prime} \in N[e]} h\left(e^{\prime}\right)=1$. This implies that $e \in B_{h}^{\prime}$.

Hence it follows that $B_{f_{1}}^{\prime} \cap B_{f_{2}}^{\prime} \subseteq B_{h}^{\prime}$.
Suppose $e \notin B_{f_{1}}^{\prime} \quad$ or $\quad e \notin B_{f_{2}}^{\prime}$.

Then $\sum_{e^{\prime} \in N[e]} f_{1}\left(e^{\prime}\right)>1$ or $\sum_{e^{\prime} \in N[e]} f_{2}\left(e^{\prime}\right)>1$.

Now

$$
\begin{aligned}
\sum_{e^{\prime} \in N[e]} h\left(e^{\prime}\right) & =\sum_{e^{\prime} \in N[e]}\left[\sum_{i=1}^{2} \lambda_{i} f_{i}\right]\left(e^{\prime}\right) \\
& =\lambda_{1} \sum_{e^{\prime} \in N[e]} f_{1}\left(e^{\prime}\right)+\lambda_{2} \sum_{e^{\prime} \in N[e]} f_{2}\left(e^{\prime}\right) \\
& >\lambda_{1} \cdot 1+\lambda_{2} \cdot 1=\lambda_{1}+\lambda_{2}=1 .
\end{aligned}
$$

Therefore $\sum_{e^{\prime} \in N[e]} h\left(e^{\prime}\right)>1$.

This implies that $e \notin B_{h}^{\prime}$.

Thus it follows that $B_{h}^{\prime} \subseteq B_{f_{1}}^{\prime} \cap B_{f_{2}}^{\prime}$

Hence from (1) and (2), we get $B_{h}^{\prime}=B_{f_{1}}^{\prime} \cap B_{f_{2}}^{\prime}$.

Now let $e \in P_{f_{1}}^{\prime} \cup P_{f_{2}}^{\prime}$.

Then either $f_{1}(e)>0$ or $f_{2}(e)>0$.

So $\lambda_{1} f_{1}(e)+\lambda_{2} f_{2}(e)>0$ and hence $h(e)>0$.

This implies that $e \in P_{h}^{\prime}$.

Thus $P_{f_{1}}^{\prime} \cup P_{f_{2}}^{\prime} \subseteq P_{h}^{\prime}$.

Suppose $e \notin P_{f_{1}}^{\prime} \cup P_{f_{2}}^{\prime}$. Then $e \notin P_{f_{1}}^{\prime}$ and $e \notin P_{f_{2}}^{\prime}$.

This implies $f_{1}(e)=0$ and $f_{2}(e)=0$.

Hence it follows that $h(e)=0$.

This implies that $e \notin P_{h}^{\prime}$

Thus $P_{h}^{\prime} \subseteq P_{f_{1}}^{\prime} \cup P_{f_{2}}^{\prime}$.

Hence from (3) and (4), it follows that $P_{f_{1}}^{\prime} \cup P_{f_{2}}^{\prime}=P_{h}^{\prime}$.

Therefore the theorem follows.

Theorem 2.3: Let $f_{1}: E \rightarrow[0,1]$ and $f_{2}: E \rightarrow[0,1]$ be two distinct MEDFs of $G\left(Z_{p}, Q\right)$. The convex combination of $f_{1}$ and $f_{2}$ is a MEDF if and only if $B_{f_{1}}^{\prime} \cap B_{f_{2}}^{\prime} \rightarrow P_{f_{1}}^{\prime} \cup P_{f_{2}}^{\prime}$ in $\mathrm{G}\left(\mathrm{Z}_{\mathrm{p}}, \mathrm{Q}\right)$.

Proof: Consider $\mathrm{G}\left(\mathrm{Z}_{\mathrm{p}}, \mathrm{Q}\right)$. Let $f_{1}$ and $f_{2}$ be two distinct MEDFs.

Let $h=\lambda_{1} f_{1}+\lambda_{2} f_{2}$, where $0<\lambda_{1}<1,0<\lambda_{2}<1$, and $\lambda_{1}+\lambda_{2}=1$.

By Theorem 2.2 we have $B_{h}^{\prime}=B_{f_{1}}^{\prime} \cap B_{f_{2}}^{\prime} \quad$ and $P_{h}^{\prime}=P_{f_{1}}^{\prime} \cup P_{f_{2}}^{\prime}$. Now by Theorem $1.1, \mathrm{~h}$ is a MEDF if and only if $B_{h}^{\prime} \rightarrow P_{h}^{\prime}$. Hence it follows that $\mathrm{h}$ is a MEDF if and only if $B_{f_{1}}^{\prime} \cap B_{f_{2}}^{\prime} \rightarrow P_{f_{1}}^{\prime} \cup P_{f_{2}}^{\prime}$ in $\mathrm{G}\left(\mathrm{Z}_{\mathrm{p}}, \mathrm{Q}\right)$.

Theorem 2.4: Let $f_{1}, f_{2}, \ldots, f_{n}$ be $n$ distinct MEDFs of $\mathrm{G}\left(\mathrm{Z}_{\mathrm{p}}, \mathrm{Q}\right)$. The convex combination of $f_{1}, f_{2}, \ldots, f_{n}$ is a 
MEDF if and only if

$$
B_{f_{1}}^{\prime} \cap B_{f_{2}}^{\prime} \cap \ldots \cap B_{f_{n}}^{\prime} \rightarrow P_{f_{1}}^{\prime} \cup P_{f_{2}}^{\prime} \cup \ldots \cup P_{f_{n}}^{\prime} .
$$

Proof: Let $f_{1}, f_{2}, \ldots, f_{n}$ be $\mathrm{n}$ distinct MEDFs of $\mathrm{G}\left(\mathrm{Z}_{\mathrm{p}}, \mathrm{Q}\right)$.

Let $\mathrm{h}$ be a convex combination of $f_{1}, f_{2}, \ldots, f_{n}$,

i.e., $h=\lambda_{1} f_{1}+\lambda_{2} f_{2}+\ldots+\lambda_{n} f_{n}$,

where $0<\lambda_{i}<1,(i=1,2,3, \ldots, n)$ and $\sum_{i=1}^{n} \lambda_{i}=1$.

We first claim that $B_{h}^{\prime}=B_{f_{1}}^{\prime} \cap B_{f_{2}}^{\prime} \cap \ldots \cap B_{f_{n}}^{\prime} \quad$ and $P_{h}^{\prime}=P_{f_{1}}^{\prime} \cup P_{f_{2}}^{\prime} \cup \ldots \cup P_{f_{n}}^{\prime}$.

Let $e \in B_{f_{1}}^{\prime} \cap B_{f_{2}}^{\prime} \cap \ldots \cap B_{f_{n}}^{\prime}$.

Then $\sum_{e^{\prime} \in N[e]} f_{i}\left(e^{\prime}\right)=1$, for $i=1,2, \ldots, n$.

Now

$$
\begin{aligned}
\sum_{e^{\prime} \in N[e]} h\left(e^{\prime}\right) & =\sum_{e^{\prime} \in N[e]}\left[\sum_{i=1}^{n} \lambda_{i} f_{i}\right]\left(e^{\prime}\right) \\
& =\sum_{e^{\prime} \in N[e]}\left[\lambda_{1} f_{1}\left(e^{\prime}\right)+\lambda_{2} f_{2}\left(e^{\prime}\right)+\ldots . .+\lambda_{n} f_{n}\left(e^{\prime}\right)\right] \\
& =\lambda_{1} \sum_{e^{\prime} \in N[e]} f_{1}\left(e^{\prime}\right)+\lambda_{2} \sum_{e^{\prime} \in N[e]} f_{2}\left(e^{\prime}\right)+\ldots+\lambda_{n} \sum_{e^{\prime} \in N[e]} f_{n}\left(e^{\prime}\right) \\
& =\lambda_{1} \cdot 1+\lambda_{2} \cdot 1+\ldots+\lambda_{n} \cdot 1 \\
& =\lambda_{1}+\lambda_{2}+\ldots+\lambda_{n}=1 .
\end{aligned}
$$

This implies that $e \in B_{h}^{\prime}$.

Hence $\quad \mathbf{I}_{i=1}^{n} B_{f_{i}}^{\prime} \subseteq B_{h}^{\prime}$.

Suppose $e \notin B_{f_{i}}^{\prime}$ for some i. Then $\sum_{e^{\prime} \in N[e]} f_{i}\left(e^{\prime}\right)>1$.

So $\sum_{e^{\prime} \in N[e]} h\left(e^{\prime}\right)>1$. This implies that $e \notin B_{h}^{\prime}$.

Thus it follows that $B_{h}^{\prime} \subseteq \coprod_{i=1}^{n} B_{f_{i}}^{\prime}$

Hence from (1) and (2) we get $B_{h}^{\prime}=\coprod_{i=1}^{n} B_{f_{i}}^{\prime}$.

Now let $e \in \bigcup_{i=1}^{n} P_{f_{i}}^{\prime}$.

This implies that $e \in P_{f_{i}}^{\prime}$ for some i, so that $f_{i}(e)>0$.

Hence it follows that $\mathrm{h}(\mathrm{e})>0$,

since $h(e)=\lambda_{1} f_{1}+\lambda_{2} f_{2}+\ldots+\lambda_{n} f_{n}>0$.

This implies that $e \in P_{h}^{\prime}$.

Therefore we have $\bigcup_{i=1}^{n} P_{f_{i}}^{\prime} \subseteq P_{h}^{\prime}$

Suppose if $e \notin \bigcup_{i=1}^{n} P_{f_{i}}^{\prime}$, then $e \notin P_{f_{i}}^{\prime}$ for each i.

Hence it follows that $f_{i}(e)=0$, for each i.
This implies that $\mathrm{h}(\mathrm{e})=0$.

Thus we have $P_{h}^{\prime} \subseteq \bigcup_{i=1}^{n} P_{f_{i}}^{\prime}$

From (3) and (4), it follows that $P_{h}^{\prime}=\bigcup_{i=1}^{n} P_{f_{i}}^{\prime}$.

Now by Theorem 1.1, it follows that $\mathrm{h}$ is a MEDF if and only if $B_{h}^{\prime} \rightarrow P_{h}^{\prime}$.

Hence $\mathrm{h}$ is a MEDF if and only if $\coprod_{i=1}^{n} B_{f_{i}}^{\prime} \rightarrow \bigcup_{i=1}^{n} P_{f_{i}}^{\prime}$.

Lemma 2.5: If the convex combination of a collection of MEDFs $f_{1}, f_{2}, \ldots, f_{n}$ is minimal in $\mathrm{G}\left(\mathrm{Z}_{\mathrm{p}}, \mathrm{Q}\right)$, then the convex combination of any proper sub-collection of $f_{1}, f_{2}, \ldots, f_{n}$ is also minimal in $\mathrm{G}\left(\mathrm{Z}_{\mathrm{p}}, \mathrm{Q}\right)$.

Proof: Let $f_{1}, f_{2}, \ldots, f_{n}$ be the collection of MEDFs of $\mathrm{G}\left(\mathrm{Z}_{\mathrm{p}}, \mathrm{Q}\right)$. Suppose the convex combination of $f_{1}, f_{2}, \ldots, f_{n}$ is minimal. Then by Theorem 2.4, it follows that $B_{f_{1}}^{\prime} \cap B_{f_{2}}^{\prime} \cap \ldots \cap B_{f_{n}}^{\prime} \rightarrow P_{f_{1}}^{\prime} \cup P_{f_{2}}^{\prime} \cup \ldots \cup P_{f_{n}}^{\prime}$.

Let $f_{1}^{\prime}, f_{2}^{\prime}, \ldots, f_{m}^{\prime}$, where $\mathrm{m}<\mathrm{n}$, be a sub-collection of $f_{1}, f_{2}, \ldots, f_{n}$. Then $\mathrm{I}_{j=1}^{m} B_{f_{j}^{\prime}}^{\prime} \supseteq \coprod_{i=1}^{n} B_{f_{i}}^{\prime}$ and $\bigcup_{j=1}^{m} P_{f_{j}^{\prime}}^{\prime} \subseteq \bigcup_{i=1}^{n} P_{f_{i}}^{\prime}$.

Since $\coprod_{i=1}^{n} B_{f_{i}}^{\prime} \rightarrow \bigcup_{i=1}^{n} P_{f_{i}}^{\prime}$, it follows that $\prod_{j=1}^{m} B_{f_{j}^{\prime}}^{\prime} \rightarrow \bigcup_{j=1}^{m} P_{f_{j}}^{\prime}$.

Thus the convex combination of $f_{1}^{\prime}, f_{2}^{\prime}, \ldots, f_{m}^{\prime}$ is a MEDF of $G\left(Z_{p}, Q\right)$.

\section{REFERENCES}

[1] Arumugam, S., and Sithara Jerry. - Fractional edge domination in graphs, Appl. Anal. Discrete Math. 3 (2009), 359-370.

[2] Arumugam, S., and Velammal, S. - Edge domination in graphs, Taiwanese Journal of Mathematics, 2 (2) (1998), 173-179.

[3] Cockayne, E. J., and Mynhardt, C. M. - Convexity of extremal domination-related functions of graphs. In Domination in Graphs - Advanced Topics, (Ed. T. W. Haynes, S. T. Hedetniemi, P. J. Slater), Dekker, Inc., New York, (1998), 109-131.

[4] Haynes, T. W., Hedetniemi, S. T., and Slater, P. J. Fundamentals of domination in graphs, Marcel Dekker, Inc., New York (1998).

[5] Haynes, T. W., Hedetniemi, S. T., and Slater, P. J. Domination in Graphs: Advanced Topics, Marcel Dekker, Inc., New York (1998).

[6] Mitchell, S., and Hedetniemi, S. T. - Edge domination in trees. Congr. Numer, 19, (1977), 489-509. 